\title{
From the IALL President
}

\author{
Nina Garrett \\ CTW Mellon Project
}

I'm delighted to be able to join my distinguished colleague, Professor Hatori, in making this issue of the IALL Journal an introduction to and celebration of our two organizations and their long-standing friendship, and-for those of you who find this issue in your conference packets-a welcome to the conference that renews that friendship, FLEAT III.

In a very real sense the contents of this issue sketch out not only the history of two professional organizations but also the history of a profession. Since the 1960s, IALL (then NALLD, the National Association of Language Lab Directors) and LLA have shaped language educators' recognition of the importance of technology in enhancing and extending language learning. Though the particular technologies have changed beyond any 1960s imaginings, the over-arching vision and the goals have not changed, and the expertise we have developed is coming to be seen as a significant factor in shaping the language learning experience at all levels. Our models for integrating the use of audio into classwork, homework, and independent study changed language pedagogy significantly three decades ago. Now, we are expanding those models to include the integration of truly interactive com-

"The warm relationship between IALL and LLA... leads us to realize the benefits of connecting and sharing with our colleagues world-wide." puter-based audio, video, text processing, and network communication and exploration as well. Academic computing support staff working across all disciplines are sometimes not aware of the in-depth audio expertise of IALL and LLA members when it is not yet computer-based. We need to establish not only the significance of our technical understanding of audio and its challenges but also the significance of our long track record in faculty training and support as a basis for shaping potentially even more radical changes in language learning in this decade and the next.

The warm relationship between IALL and LLA-and, across the other ocean, with EuroCALL as well-leads us to realize the benefits of connecting and sharing with our colleagues world-wide. Surely there is no other segment of academe 
better able than professionals in language learning and technology to understand the value of communicating across national, language, and geographical boundaries! I hope that this sense of partnership will bring many of us together, at WorldCALL in Australia in 1998, with still more colleagues from around the globe in what is surely one of the most exciting professions in the world. Meanwhile, I look forward eagerly to joining with our colleagues from Japan in greeting old friends and making new ones at FLEAT III. 